\title{
Erratum to: A novel TMV-induced hot pepper cell wall protein gene (CaTin2) is associated with virus-specific hypersensitive response pathway
}

\author{
Ryoung Shin • Chang-Jin Park · Jong-Min An • \\ Kyung-Hee Paek
}

Published online: 10 April 2013

(C) Springer Science+Business Media Dordrecht 2013

\section{Erratum to: Plant Molecular Biology (2003) 51:687-701 \\ DOI 10.1023/A:1022599213648}

Due to an unfortunate turn of events, incorrect versions of Figs. 3A, 3C, 4, 5A, and 5B have been used in the abovementioned publication. The authors apologize for inserting incorrect rRNA control pictures and have provided corrected versions in Figs. 3a, c, 4, and 5a, b that should be treated as definitive by the reader.



Fig. 3 a Differential expression pattern of CaTin2 gene upon inoculation with TMV- $\mathrm{P}_{0}$ (avirulent) or TMV- $\mathrm{P}_{1.2}$ (virulent). Total RNA was extracted from leaves at $0,6,12,24$, and $48 \mathrm{~h}$ after inoculation. As a control, leaves were mock inoculated with extraction buffer. RNA was separated in a formaldehyde-agarose gel, and the blot was hybridized with the ${ }^{32} \mathrm{P}$-labeled CaTin 2 fulllength cDNA probe. The rRNA bands in ethidium bromide-stained gels are shown as a loading control. The CaPRl gene was used as a positive control for TMV inoculation. Results are representative of four independent experiments. c Expression pattern of pepper CaTin2 gene upon Xanthomonas campestiris inoculation. A hot pepper cultivar (ECW-20R) resistant to X. campestiris pv. vesicatoria $(X c v)$ race 3 and a susceptible cultivar (ECW) were infiltrated with culture. Total RNA was extracted from the leaves harvested at indicated time points after inoculation. RNA was separated in formaldehyde-agarose gel and transferred onto a nylon membrane. The membrane was hybridized with the ${ }^{32} \mathrm{P}$-labeled full-length CaTin2 cDNA probe. The CaPR1 gene was used as a positive control. The CaTin2 blot was exposed longer than $C a P R I$ blot on purpose to reveal the background. The rRNA bands in ethidium bromide-stained gels are shown as a loading control. A typical result from three independent experiments is shown

R. Shin · C.-J. Park · J.-M. An · K.-H. Paek $(\bowtie)$

Graduate School of Biotechnology, Korea University, 1, 5-ga, Anam-dong, Sungbuk-gu, Seoul 136-701, Korea

e-mail: khpaek95@korea.ac.kr 


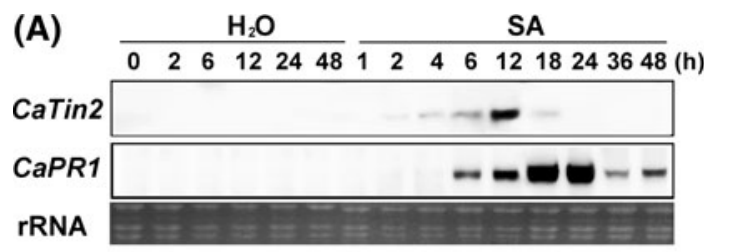

(B)

$\mathrm{H}_{2} \mathrm{O}$

Ethylene


Fig. 4 Expression pattern of CaTin2 gene by SA, ethylene or MeJA treatment. a Transcripts of CaTin2 gene were monitored after SA treatment. Pepper leaves were sprayed with a solution of $5 \mathrm{mM} \mathrm{SA}$. b Transcripts of CaTin2 gene were monitored after ethylene treatment. Pepper plants were kept in a chamber equilibrated with $50 \mu \mathrm{l} / \mathrm{L}$ gaseous ethylene for the time period indicated. Control experiments were carried out in an identical chamber without ethylene. c Time course of accumulation of CaTin2 transcripts detected upon $10 \mu \mathrm{M}$ MeJA treatment. Gel blots of hormone-treated hot pepper leaf total RNA were hybridized with the ${ }^{32} \mathrm{P}$-labeled CaTin2 full-length cDNA probe. The rRNA bands in ethidium bromide-stained gels are shown as a loading control. The $C a P R l$ gene in case of SA and ethylene treatments and the CaPR4 gene in MeJA treatment were used as positive controls. Experiments were performed at least three times for each treatment, and the representative result is shown here
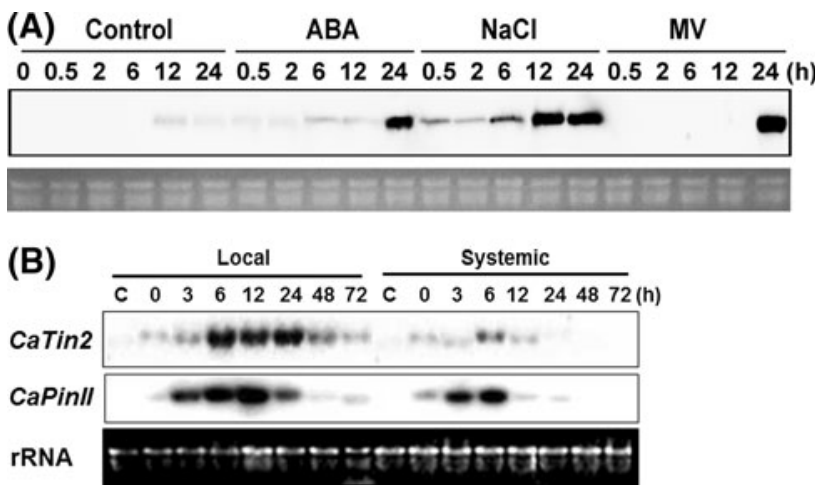

Fig. 5 Expression pattern of CaTin2 gene by ABA, $\mathrm{NaCl}$, methyl viologen (MV), wounding or dark treatment. a For the treatments of ABA $(5 \mu \mathrm{M}), \mathrm{NaCl}(400 \mathrm{mM})$, or methyl viologen $(0.5 \mathrm{mM})$, unrooted pepper plants were placed in Falcon tubes filled with each chemical or water for various time periods and then frozen in liquid nitrogen for further analyses. b Accumulation of CaTin2 transcripts was monitored after local and systemic incision-wounding treatment. Pepper leaves to which the cutting was applied (local) and upper uninoculated leaves of the same plant (systemic) were harvested at the indicated time points, respectively. The gel blots of hormone or wound-treated hot pepper leaf total RNA were hybridized with the ${ }^{32}$ P-labeled CaTin2 full-length cDNA probe. Experiments were performed at least three times for each treatment, and the representative result is shown here 